\title{
Market Sentiment Deterioration and Stock Returns: The Case of the Japanese Electric Appliances Industry
}

\author{
Chikashi Tsuji \\ Correspondence: Chikashi Tsuji, Graduate School of Systems and Information Engineering, University of Tsukuba, \\ 1-1-1 Tennodai, Tsukuba, Ibaraki 305-8573, Japan. Tel: 81-29-853-2111. E-mail: mail_sec_low@minos.ocn.ne.jp
}

\author{
Received: March 13, 2012 \\ Accepted: April 6, 2012 \\ Published: June 1, 2012 \\ doi:10.5539/ijef.v4n6p63 \\ URL: http://dx.doi.org/10.5539/ijef.v4n6p63
}

The research is financed by the Japan Society for the Promotion of Science and the author greatly acknowledges their generous financial assistance for this research.

\begin{abstract}
This paper aims to clarify the characteristics of the return dynamics of the Japanese electric appliances industry stocks in markets with deteriorated investor sentiment. The contributions derived by our empirical analysis are as follows. First, this paper newly clarifies that high beta stocks show conjunctional behavior when investor sentiment is deteriorated in stock markets. Second, we also clarify that high size stocks also exhibit conjunctional behaviors in markets with deteriorated sentiment. Moreover, we further demonstrate that the conjunctional behaviors of high beta stocks and high size stocks do not have the same behavioral characteristics in markets with extremely declined investor sentiment.
\end{abstract}

Keywords: high beta stocks, implied volatility, investor sentiment, high size stocks

\section{Introduction}

Investor sentiment in financial markets is more and more paid attention to by academic researchers and practitioners. Representative academic researches with respect to this market sentiment were implemented by such studies as Lee et al. (1991), Barberis et al. (1998), Neal and Wheatley (1998), Daniel et al, (1998), Baker and Wurgler (2006), and Baker and Wurgler (2007). In addition, many new researches follow the above studies as seen in Tsuji (2006), Kurov (2010), Berger and Turtle (2012), Baker et al. (2012), Alimov and Mikkelson (2012), and Stambaugh et al. (2012). However, as far as we know, there seems to be little study which investigates the stock return dynamics when market sentiment is deteriorated. Focusing on this point, therefore, this paper aims to clarify the characteristics of return dynamics of the Japanese equities when market sentiment is deteriorated. This is our main objective of this paper. We focus on the Japanese electric appliances industry stocks because this is one of the most representative industries in Japan.

Our contributions in this paper are as follows. First, this paper newly clarifies that high beta stocks show conjunctional behavior when investor sentiment is deteriorated in stock markets. Second, we also clarify that large size stocks also exhibit conjunctional behavior when market sentiment is extremely declined. In addition, we further demonstrate that the conjunctional behaviors of high beta stocks and big size stocks do not have the same behavioral characteristics in markets with deteriorated investor sentiment.

The rest of the paper is organized as follows. First, Section 2 conducts literature review, Section 3 explains data and model, Section 4 presents the empirical results and interpretations, and Section 5 summarizes the paper.

\section{Literature Review}

This section briefly reviews the existing related literature. First, Barberis et al. (1998) and Daniel et al. (1998) build models of investor sentiment, and Lee et al. (1991) analyze the relation between investor sentiment and the closed-end fund puzzle. Further, Neal and Wheatley (1998), Baker and Wurgler (2006, 2007), Tsuji (2006), Berger and Turtle (2012), Baker et al. (2012), and Stambaugh et al. (2012) perform empirical analysis of investor sentiment in stock markets in general contexts. Above are all interesting and exciting studies, however, as we mentioned, there seems to be little study which investigates the stock return dynamics by focusing on the stock markets with deteriorated investor sentiment.

\section{Data and Empirical Model}

This section explains the data and our empirical model. Regarding the relations between market sentiment and stock 
returns, there would not be perfect theory, thus we later introduce the empirical model. First, the full universe of our data of implied volatility (IV), which is an investor sentiment measure, is from January 5, 1998 to April 28, 2011. Namely, our implied volatility data derived from the Nikkei 225 options (from Osaka University) have daily frequency. By using these IV values and other data, we design our empirical research. To design our research effectively, we focus on extremely high IV dates in our above full samples. More specifically, for our empirical tests, we regard extremely high IV dates as those when IV exceeds the value of 80.0. As displayed from Tables 1 to 4, only 11 days are recognized as extremely high IV dates; namely these eleven days are the dates when market sentiment is deteriorated in our setting.

Table 1. The Results of Regressions: October 16, 27, and 28 in 2008

\begin{tabular}{|c|c|c|c|c|c|c|c|c|c|}
\hline & \multicolumn{5}{|c|}{ Statistics of the Japanese Electric Appliances Industry Stock Returns } & & & & \\
\hline & \multicolumn{3}{|c|}{ October 16,2008} & \multicolumn{3}{|c|}{ October 27,2008} & \multicolumn{3}{|c|}{ October 28, 2008} \\
\hline & Mean & Min. & Max. & Mean & Min. & Max. & Mean & Min. & Max. \\
\hline & -10.193 & -18.957 & 1.036 & -6.677 & -26.667 & 5.213 & 8.027 & -7.216 & 24.316 \\
\hline & SD. & Skewness & Kurtosis & SD. & Skewness & Kurtosis & SD. & Skewness & Kurtosis \\
\hline & 4.411 & 0.381 & 2.642 & 4.857 & -0.447 & 4.727 & 6.080 & 0.220 & 3.151 \\
\hline \multicolumn{10}{|c|}{ Panel B Estimation Results } \\
\hline & \multicolumn{3}{|c|}{ October 16,2008} & \multicolumn{3}{|c|}{ October 27, 2008} & \multicolumn{3}{|c|}{ October 28, 2008} \\
\hline & Model 1 & Model 2 & Model 3 & Model 1 & Model 2 & Model 3 & Model 1 & Model 2 & Model 3 \\
\hline Constant & $-5.681^{*}$ & $11.088 * *$ & $9.175^{*}$ & 3.290 & $12.077 * *$ & $11.300^{*}$ & $9.753 * *$ & $-14.241 *$ & $-15.934 *$ \\
\hline$p$-value & 0.067 & 0.033 & 0.088 & 0.351 & 0.035 & 0.059 & 0.049 & 0.087 & 0.055 \\
\hline BETA & $-5.019 * * *$ & & $-4.073 * * *$ & -2.164 & & -1.638 & -1.123 & & -2.856 \\
\hline$p$-value & 0.001 & & 0.006 & 0.190 & & 0.327 & 0.585 & & 0.178 \\
\hline SIZE & & $-1.471 * * *$ & $-1.237 * * *$ & & $-0.786^{* *}$ & $-0.709 *$ & & $2.024 * * *$ & $2.178 * * *$ \\
\hline$p$-value & & 0.000 & 0.001 & & 0.045 & 0.078 & & 0.000 & 0.000 \\
\hline $\mathrm{BM}$ & 0.387 & $-1.547 * *$ & -0.748 & -1.653 & $-2.441 * *$ & $-2.121 *$ & -1.013 & 0.083 & 0.718 \\
\hline$p$-value & 0.605 & 0.032 & 0.352 & 0.127 & 0.012 & 0.065 & 0.296 & 0.924 & 0.472 \\
\hline VOL & 0.015 & $0.196^{*}$ & $0.184^{*}$ & -0.024 & 0.058 & 0.058 & 0.027 & -0.335 & -0.335 \\
\hline$p$-value & 0.854 & 0.069 & 0.080 & 0.783 & 0.485 & 0.479 & 0.799 & 0.150 & 0.144 \\
\hline TDTA & 0.007 & -0.036 & -0.007 & -0.043 & $-0.061 * *$ & -0.049 & 0.023 & 0.027 & 0.050 \\
\hline$p$-value & 0.823 & 0.230 & 0.829 & 0.238 & 0.046 & 0.169 & 0.646 & 0.549 & 0.284 \\
\hline LAR & 0.021 & 0.016 & 0.013 & -0.002 & -0.006 & 0.006 & 0.040 & 0.054 & 0.055 \\
\hline$p$-value & 0.662 & 0.741 & 0.760 & 0.964 & 0.907 & 0.914 & 0.508 & 0.355 & 0.336 \\
\hline CFPS & $-0.003 *$ & -0.001 & -0.001 & -0.001 & 0.000 & 0.000 & 0.000 & -0.003 & -0.003 \\
\hline$p$-value & 0.088 & 0.476 & 0.564 & 0.833 & 0.887 & 0.857 & 0.974 & 0.222 & 0.241 \\
\hline BEP & -0.006 & -0.204 & -0.082 & $-0.335^{*}$ & $-0.420 * * *$ & $-0.363 * *$ & -0.061 & -0.046 & 0.058 \\
\hline$p$-value & 0.963 & 0.118 & 0.532 & 0.053 & 0.008 & 0.042 & 0.750 & 0.767 & 0.748 \\
\hline Adj. $R^{2}$ & 0.121 & 0.135 & 0.190 & 0.074 & 0.088 & 0.087 & -0.028 & 0.079 & 0.085 \\
\hline Obs. & 116 & 116 & 116 & 116 & 116 & 116 & 116 & 116 & 116 \\
\hline
\end{tabular}

Notes: We use the data of the Japanese electric appliances industry and implied volatilities derived from the Nikkei 225 options. Our full samples are 3,274 and the full daily sample period is from January 5, 1998 to April 28, 2011. We regard the markets when IV exceeds 80.0 as stock markets with deteriorated sentiment, and we perform the cross-sectional regressions for the days when market sentiment is deteriorated. Model 1 examines the beta effect with controlling the variables, BM, VOL, TDTA, LAR, CFPS, and BEP. Model 2 tests the size effect with controlling the variables, BM, VOL, TDTA, LAR, CFPS, and BEP. Further, Model 3 examines both beta and size effects with controlling the variables, BM, VOL, TDTA, LAR, CFPS, and BEP. In panel A, 'Min.' denotes minimum value, 'Max.' denotes maximum value, and 'SD.' denotes standard deviation, respectively. In panel B, 'Constant' denotes constant term, BETA denotes the beta values of sample firms, SIZE means the market capitalization values of sample firms, BM denotes the book-to-market ratios of sample firms, and VOL means the yen trading volumes of sample firms. Further, TDTA means debt ratios of sample firms, LAR denotes the short-term liquidity to total asset ratios of sample firms, CFPS means the cash-flow per share, and BEP denotes EBITs to total asset ratios. Moreover, Adj. $R^{2}$ denotes the adjusted $R$-squared values and Obs. means the number of samples in our cross-sectional regressions. Further, we use the method of White (1980), thus $p$-values are robust to the heteroskedasticity of the error terms of regressions. $* * *$ denotes the statistical significance at the $1 \%$ level, $* *$ denotes the statistical significance at the $5 \%$ level, and * denotes the statistical significance at the $10 \%$ level, respectively. 
Table 2. The Results of Regressions: October 29, 30, and 31 in 2008

\begin{tabular}{|c|c|c|c|c|c|c|c|c|c|}
\hline \multirow[t]{3}{*}{ Panel A } & \multicolumn{9}{|c|}{ Statistics of the Japanese Electric Appliances Industry Stock Returns } \\
\hline & \multicolumn{3}{|c|}{ October 29,2008} & \multicolumn{3}{|c|}{ October 30,2008} & \multicolumn{3}{|c|}{ October 31,2008} \\
\hline & Mean & Min. & Max. & Mean & Min. & Max. & Mean & Min. & Max. \\
\hline & 5.759 & -9.028 & 20.253 & 7.772 & -3.049 & 22.346 & -2.536 & -19.540 & 16.076 \\
\hline & SD. & Skewness & Kurtosis & SD. & Skewness & Kurtosis & SD. & Skewness & Kurtosis \\
\hline & 5.526 & 0.265 & 3.261 & 4.332 & 0.079 & 3.725 & 4.476 & -0.119 & 5.948 \\
\hline \multicolumn{10}{|c|}{ Panel B $\quad$ Estimation Results } \\
\hline & \multicolumn{3}{|c|}{ October 29, 2008} & \multicolumn{3}{|c|}{ October 30, 2008} & \multicolumn{3}{|c|}{ October 31, 2008} \\
\hline & Model 1 & Model 2 & Model 3 & Model 1 & Model 2 & Model 3 & Model 1 & Model 2 & Model 3 \\
\hline Constant & $7.549 * *$ & -5.915 & -4.629 & $5.448^{*}$ & -7.126 & -5.290 & 1.346 & $22.456^{* * *}$ & $20.375^{* * *}$ \\
\hline$p$-value & 0.022 & 0.436 & 0.547 & 0.060 & 0.230 & 0.382 & 0.633 & 0.000 & 0.000 \\
\hline BETA & $3.069^{*}$ & & 2.254 & $3.679 * * *$ & & $2.965 * *$ & $-4.835^{* * *}$ & & $-3.529 * *$ \\
\hline$p$-value & 0.094 & & 0.217 & 0.006 & & 0.025 & 0.001 & & 0.013 \\
\hline SIZE & & $1.147 * *$ & $1.023^{*}$ & & $1.076^{* * *}$ & $0.899 * *$ & & $-1.816^{* * *}$ & $-1.629 * * *$ \\
\hline$p$-value & & 0.028 & 0.055 & & 0.006 & 0.024 & & 0.000 & 0.000 \\
\hline $\mathrm{BM}$ & $-1.873 * *$ & -0.518 & -1.014 & $-1.175^{*}$ & 0.306 & -0.384 & 0.600 & $-1.588 * *$ & -0.742 \\
\hline$p$-value & 0.024 & 0.526 & 0.284 & 0.091 & 0.632 & 0.617 & 0.367 & 0.013 & 0.302 \\
\hline VOL & -0.156 & $-0.330 * * *$ & $-0.327 * * *$ & -0.009 & -0.164 & -0.156 & -0.091 & 0.162 & 0.159 \\
\hline$p$-value & 0.272 & 0.004 & 0.004 & 0.928 & 0.143 & 0.170 & 0.548 & 0.139 & 0.156 \\
\hline TDTA & -0.035 & -0.004 & -0.021 & 0.005 & 0.041 & 0.017 & -0.002 & -0.048 & -0.019 \\
\hline$p$-value & 0.316 & 0.909 & 0.552 & 0.866 & 0.199 & 0.607 & 0.943 & 0.126 & 0.566 \\
\hline LAR & $-0.093 * *$ & $-0.086^{*}$ & $-0.086^{*}$ & -0.003 & 0.004 & 0.003 & 0.053 & 0.040 & 0.042 \\
\hline$p$-value & 0.037 & 0.067 & 0.057 & 0.944 & 0.925 & 0.938 & 0.198 & 0.249 & 0.244 \\
\hline CFPS & $0.006^{* * *}$ & $0.004 * *$ & $0.004 *$ & 0.002 & 0.001 & 0.001 & -0.000 & 0.002 & 0.002 \\
\hline$p$-value & 0.010 & 0.047 & 0.055 & 0.285 & 0.521 & 0.607 & 0.963 & 0.595 & 0.570 \\
\hline BEP & 0.053 & 0.193 & 0.112 & -0.020 & 0.133 & 0.028 & -0.074 & $-0.276^{* *}$ & -0.146 \\
\hline$p$-value & 0.749 & 0.219 & 0.520 & 0.876 & 0.323 & 0.832 & 0.588 & 0.031 & 0.277 \\
\hline Adj. $R^{2}$ & 0.174 & 0.195 & 0.198 & 0.080 & 0.087 & 0.109 & 0.126 & 0.214 & 0.246 \\
\hline Obs. & 116 & 116 & 116 & 116 & 116 & 116 & 116 & 116 & 116 \\
\hline
\end{tabular}

Notes: We use the data of the Japanese electric appliances industry and implied volatilities derived from the Nikkei 225 options. Our full samples are 3,274 and the full daily sample period is from January 5, 1998 to April 28, 2011. We regard the markets when IV exceeds 80.0 as stock markets with deteriorated sentiment, and we perform the cross-sectional regressions for the days when market sentiment is deteriorated. Model 1 examines the beta effect with controlling the variables, BM, VOL, TDTA, LAR, CFPS, and BEP. Model 2 tests the size effect with controlling the variables, BM, VOL, TDTA, LAR, CFPS, and BEP. Further, Model 3 examines both beta and size effects with controlling the variables, BM, VOL, TDTA, LAR, CFPS, and BEP. In panel A, 'Min.' denotes minimum value, 'Max.' denotes maximum value, and 'SD.' denotes standard deviation, respectively. In panel B, 'Constant' denotes constant term, BETA denotes the beta values of sample firms, SIZE means the market capitalization values of sample firms, BM denotes the book-to-market ratios of sample firms, and VOL means the yen trading volumes of sample firms. Further, TDTA means debt ratios of sample firms, LAR denotes the short-term liquidity to total asset ratios of sample firms, CFPS means the cash-flow per share, and BEP denotes EBITs to total asset ratios. Moreover, Adj. $R^{2}$ denotes the adjusted $R$-squared values and Obs. means the number of samples in our cross-sectional regressions. Further, we use the method of White (1980), thus $p$-values are robust to the heteroskedasticity of the error terms of regressions. ${ }^{* * *}$ denotes the statistical significance at the $1 \%$ level, $* *$ denotes the statistical significance at the $5 \%$ level, and * denotes the statistical significance at the $10 \%$ level, respectively.

Based on the above design, by also using return data and other market and accounting data (They are from Nikkei Inc.), we perform the cross-sectional regressions. Regarding accounting data, we use the data which are published at least six month before the dates of our cross-sectional regressions for the days when sentiment is extremely declined. We take the time span of six months because it needs time for market participants to understand the companies' financial conditions. Further, with respect to return data, they are 116 Japanese electric appliances industry firms' returns, and these firms are listed in the Tokyo Stock Exchange (TSE) First Section. Currently, the largest number of the electric appliances industry firms is included in the Tokyo Stock Price Index (TOPIX). Thus we consider that this industry is highly important for the Japanese equity markets, and thus we use these companies' data in this paper.

Writing our empirical model of cross-sectional regression in full form, the formula is as follows: 


$$
\begin{aligned}
R E T_{i}=\xi_{0} & +\xi_{1} B E T A_{i}+\xi_{2} S I Z E_{i} \\
& +\xi_{3} B M_{i}+\xi_{4} \text { VOL }_{i}+\xi_{5} \text { TDTA }_{i}+\xi_{6} L A R_{i}+\xi_{7} \text { CFPS }_{i}+\xi_{8} B E P_{i}+\eta_{i}
\end{aligned}
$$

Where BETA denotes the beta values of sample firms, SIZE means the market capitalization values of sample firms, BM denotes the book-to-market ratios of sample firms, and VOL means the yen trading volumes of sample firms. Further, TDTA means the debt ratios of sample firms, LAR denotes the short-term liquidity to total asset ratios of sample firms, CFPS means the cash-flow per share, and BEP denotes the EBITs to total asset ratios. We use the method of White (1980) thus statistical significance of the coefficients of our regressions is robust to heteroskedasticity of regression error terms.

\begin{tabular}{|c|c|c|c|c|c|c|c|c|c|}
\hline & \multicolumn{6}{|c|}{ Statistics of the Japanese Electric Appliances Industry Stock Returns } & & & \\
\hline & \multicolumn{3}{|c|}{ November 4, 2008} & \multicolumn{3}{|c|}{ November 7, 2008} & \multicolumn{3}{|c|}{ November 13, 2008} \\
\hline & Mean & Min. & Max. & Mean & Min. & Max. & Mean & Min. & Max. \\
\hline & 5.806 & -3.751 & 34.483 & -3.560 & -17.836 & 4.615 & -4.562 & -17.526 & 5.988 \\
\hline & SD. & Skewness & Kurtosis & SD. & Skewness & Kurtosis & SD. & Skewness & Kurtosis \\
\hline & 5.557 & 1.613 & 8.685 & 3.432 & -0.399 & 4.806 & 3.520 & -0.383 & 4.535 \\
\hline \multirow[t]{3}{*}{ Panel B } & \multicolumn{9}{|c|}{ Estimation Results } \\
\hline & \multicolumn{3}{|c|}{ November 4, 2008} & \multicolumn{3}{|c|}{ November 7, 2008} & \multicolumn{3}{|c|}{ November 13,2008} \\
\hline & Model 1 & Model 2 & Model 3 & Model 1 & Model 2 & Model 3 & Model 1 & Model 2 & Model 3 \\
\hline Constant & 1.840 & -11.739 & -9.315 & 2.433 & $10.870^{* *}$ & $8.833 *$ & -3.821 & $7.809^{*}$ & $7.659^{*}$ \\
\hline$p$-value & 0.580 & 0.178 & 0.301 & 0.237 & 0.020 & 0.063 & 0.131 & 0.071 & 0.096 \\
\hline BETA & $4.571 * *$ & & $3.710^{*}$ & $-3.821 * * *$ & & $-3.408 * * *$ & -1.148 & & -0.228 \\
\hline$p$-value & 0.028 & & 0.089 & 0.000 & & 0.001 & 0.442 & & 0.883 \\
\hline SIZE & & $1.168 * *$ & 0.934 & & $-0.748 * *$ & -0.549 & & $-1.006 * * *$ & $-0.991 * * *$ \\
\hline$p$-value & & 0.047 & 0.138 & & 0.040 & 0.146 & & 0.001 & 0.001 \\
\hline $\mathrm{BM}$ & $-1.655^{* * *}$ & 0.105 & -0.777 & -0.621 & $-1.790 * * *$ & $-1.024 * *$ & 0.378 & -0.450 & -0.400 \\
\hline$p$-value & 0.009 & 0.904 & 0.357 & 0.152 & 0.001 & 0.024 & 0.464 & 0.400 & 0.530 \\
\hline VOL & -0.044 & -0.187 & -0.176 & -0.017 & 0.098 & 0.090 & $-0.198 * * *$ & -0.003 & -0.005 \\
\hline$p$-value & 0.614 & 0.134 & 0.164 & 0.808 & 0.400 & 0.453 & 0.002 & 0.961 & 0.942 \\
\hline TDTA & 0.061 & $0.100^{* *}$ & 0.072 & -0.009 & $-0.042 * *$ & -0.016 & -0.003 & -0.015 & -0.014 \\
\hline$p$-value & 0.272 & 0.043 & 0.206 & 0.643 & 0.026 & 0.406 & 0.909 & 0.491 & 0.636 \\
\hline LAR & -0.002 & 0.007 & 0.006 & 0.004 & -0.004 & -0.002 & -0.019 & -0.026 & -0.026 \\
\hline$p$-value & 0.975 & 0.911 & 0.931 & 0.927 & 0.922 & 0.965 & 0.615 & 0.435 & 0.440 \\
\hline CFPS & 0.000 & -0.001 & -0.001 & 0.002 & $0.003^{*}$ & $0.003^{*}$ & -0.000 & 0.001 & 0.001 \\
\hline$p$-value & 0.871 & 0.736 & 0.646 & 0.142 & 0.070 & 0.052 & 0.698 & 0.265 & 0.275 \\
\hline BEP & -0.086 & 0.099 & -0.026 & -0.187 & $-0.327 * * *$ & $-0.211^{*}$ & 0.084 & 0.019 & 0.027 \\
\hline$p$-value & 0.474 & 0.458 & 0.836 & 0.101 & 0.010 & 0.064 & 0.564 & 0.870 & 0.850 \\
\hline Adj. $R^{2}$ & 0.114 & 0.111 & 0.132 & 0.121 & 0.078 & 0.134 & 0.016 & 0.090 & 0.081 \\
\hline Obs. & 116 & 116 & 116 & 116 & 116 & 116 & 116 & 116 & 116 \\
\hline
\end{tabular}

Table 3. The Results of Regressions: November 4, 7, and 13 in 2008

Notes: We use the data of the Japanese electric appliances industry and implied volatilities derived from the Nikkei 225 options. Our full samples are 3,274 and the full daily sample period is from January 5, 1998 to April 28, 2011. We regard the markets when IV exceeds 80.0 as stock markets with deteriorated sentiment, and we perform the cross-sectional regressions for the days when market sentiment is deteriorated. Model 1 examines the beta effect with controlling the variables, BM, VOL, TDTA, LAR, CFPS, and BEP. Model 2 tests the size effect with controlling the variables, BM, VOL, TDTA, LAR, CFPS, and BEP. Further, Model 3 examines both beta and size effects with controlling the variables, BM, VOL, TDTA, LAR, CFPS, and BEP. In panel A, 'Min.' denotes minimum value, 'Max.' denotes maximum value, and 'SD.' denotes standard deviation, respectively. In panel B, 'Constant' denotes constant term, BETA denotes the beta values of sample firms, SIZE means the market capitalization values of sample firms, BM denotes the book-to-market ratios of sample firms, and VOL means the yen trading volumes of sample firms. Further, TDTA means debt ratios of sample firms, LAR denotes the short-term liquidity to total asset ratios of sample firms, CFPS means the cash-flow per share, and BEP denotes EBITs to total asset ratios. Moreover, Adj. $R^{2}$ denotes the adjusted $R$-squared values and Obs. means the number of samples in our cross-sectional regressions. Further, we use the method of White (1980), thus $p$-values are robust to the heteroskedasticity of the error terms of regressions. $* * *$ denotes the statistical significance at the $1 \%$ level, ** denotes the statistical significance at the $5 \%$ level, and $*$ denotes the statistical significance at the $10 \%$ level, respectively. 
Table 4. The Results of Regressions: November 20 and 21 in 2008

\begin{tabular}{|c|c|c|c|c|c|c|}
\hline \multirow{3}{*}{ Panel A } & \multicolumn{6}{|c|}{ Statistics of the Japanese Electric Appliances Industry Stock Returns } \\
\hline & \multicolumn{3}{|c|}{ November 20, 2008} & \multicolumn{3}{|c|}{ November 21, 2008} \\
\hline & Mean & Min. & Max. & Mean & Min. & Max. \\
\hline & -4.706 & -12.141 & 22.989 & 3.571 & -21.495 & 13.404 \\
\hline & SD. & Skewness & Kurtosis & SD. & Skewness & Kurtosis \\
\hline & 3.928 & 2.797 & 22.495 & 4.081 & -1.958 & 14.167 \\
\hline \multirow[t]{3}{*}{ Panel B } & Estimation Results & & & & & \\
\hline & \multicolumn{3}{|c|}{ November 20,2008} & \multicolumn{3}{|c|}{ November 21,2008} \\
\hline & Model 1 & Model 2 & Model 3 & Model 1 & Model 2 & Model 3 \\
\hline Constant & 0.715 & $15.351 * * *$ & $15.096^{* * *}$ & $4.919 * *$ & -2.604 & -0.317 \\
\hline$p$-value & 0.782 & 0.002 & 0.006 & 0.028 & 0.587 & 0.944 \\
\hline BETA & -1.468 & & -0.344 & $3.423 * *$ & & $3.062 * *$ \\
\hline$p$-value & 0.217 & & 0.784 & 0.010 & & 0.017 \\
\hline SIZE & & $-1.259 * * *$ & $-1.239 * * *$ & & 0.629 & 0.449 \\
\hline$p$-value & & 0.000 & 0.000 & & 0.121 & 0.244 \\
\hline $\mathrm{BM}$ & -0.038 & $-1.153 * * *$ & $-1.062 * *$ & $-1.938 * *$ & -0.766 & $-1.583^{*}$ \\
\hline$p$-value & 0.939 & 0.007 & 0.035 & 0.044 & 0.345 & 0.080 \\
\hline VOL & -0.153 & 0.158 & 0.158 & -0.112 & -0.232 & -0.239 \\
\hline$p$-value & 0.261 & 0.211 & 0.212 & 0.382 & 0.205 & 0.193 \\
\hline TDTA & -0.034 & $-0.049 *$ & -0.046 & -0.022 & 0.006 & -0.018 \\
\hline$p$-value & 0.268 & 0.059 & 0.141 & 0.350 & 0.788 & 0.447 \\
\hline LAR & 0.004 & -0.003 & -0.003 & -0.007 & -0.001 & -0.004 \\
\hline$p$-value & 0.918 & 0.926 & 0.933 & 0.824 & 0.973 & 0.900 \\
\hline CFPS & $-0.003 * *$ & -0.001 & -0.001 & 0.001 & 0.000 & 0.000 \\
\hline$p$-value & 0.043 & 0.502 & 0.499 & 0.506 & 0.775 & 0.757 \\
\hline BEP & -0.236 & $-0.318^{* *}$ & $-0.304 *$ & -0.040 & 0.111 & -0.016 \\
\hline$p$-value & 0.148 & 0.025 & 0.066 & 0.745 & 0.329 & 0.893 \\
\hline Adj. $R^{2}$ & 0.161 & 0.250 & 0.244 & 0.103 & 0.079 & 0.104 \\
\hline Obs. & 116 & 116 & 116 & 116 & 116 & 116 \\
\hline
\end{tabular}

Notes: We use the data of the Japanese electric appliances industry and implied volatilities derived from the Nikkei 225 options. Our full samples are 3,274 and the full daily sample period is from January 5, 1998 to April 28, 2011. We regard the markets when IV exceeds 80.0 as stock markets with deteriorated sentiment, and we perform the cross-sectional regressions for the days when market sentiment is deteriorated. Model 1 examines the beta effect with controlling the variables, BM, VOL, TDTA, LAR, CFPS, and BEP. Model 2 tests the size effect with controlling the variables, BM, VOL, TDTA, LAR, CFPS, and BEP. Further, Model 3 examines both beta and size effects with controlling the variables, BM, VOL, TDTA, LAR, CFPS, and BEP. In panel A, 'Min.' denotes minimum value, 'Max.' denotes maximum value, and 'SD.' denotes standard deviation, respectively. In panel B, 'Constant' denotes constant term, BETA denotes the beta values of sample firms, SIZE means the market capitalization values of sample firms, BM denotes the book-to-market ratios of sample firms, and VOL means the yen trading volumes of sample firms. Further, TDTA means debt ratios of sample firms, LAR denotes the short-term liquidity to total asset ratios of sample firms, CFPS means the cash-flow per share, and BEP denotes EBITs to total asset ratios. Moreover, Adj. $R^{2}$ denotes the adjusted $R$-squared values and Obs. means the number of samples in our cross-sectional regressions. Further, we use the method of White (1980), thus $p$-values are robust to the heteroskedasticity of the error terms of regressions. ${ }^{* *}$ denotes the statistical significance at the $1 \%$ level, $* *$ denotes the statistical significance at the $5 \%$ level, and $*$ denotes the statistical significance at the $10 \%$ level, respectively.

More specifically, we perform three types of regressions. First is Model 1, which examines the beta effect with controlling the variables, BM, VOL, TDTA, LAR, CFPS, and BEP. Second is the Model 2, which tests the size effect with controlling the variables, BM, VOL, TDTA, LAR, CFPS, and BEP. Finally, Model 3 examines both beta and size effects with again controlling the variables, BM, VOL, TDTA, LAR, CFPS, and BEP. We implement our regressions only for the dates when market sentiment is deteriorated, i.e., when IV exceeds the value of 80.0.

\section{Empirical Results and Interpretations}

This section describes our empirical results. As we documented, we perform cross sectional regressions by focusing on the dates when market sentiment is deteriorated. First, Table 1 exhibits the regression results of October 16, 27 , and 28 in 2008. First, as to October 16, the variables of BETA and SIZE are statistically significant with the same sign as the mean value of returns of all Japanese electric appliances industry firms on the day in Models 1 and 2. 
These results do not change in Model 3, which includes both BETA and SIZE in our regression. This means that high beta firms and large size stocks move to the same direction on the day when market sentiment is deteriorated. Further, as to the results of October 27 and 28 in 2008, the same strong results especially for big size stocks are recognized.

Second, Table 2 demonstrates the regression results as to October 29, 30, and 31 in 2008. This table shows that similar and stronger results as those in Table 1. That is, the variables of BETA and SIZE are statistically significant with the same sign as the mean value of returns of all Japanese electric appliances industry firms on those days in Models 1, 2, and 3. Only one exception is the result for BETA in Model 3 of October 29, 2008. Hence Table 2 strongly indicates that high beta firms and large size stocks move to the same direction with conjunctional behavior when market sentiment is extremely declined.

Furthermore, Tables 3 and 4 display the regression results as to November 4, 7, 13, 20, and 21 in 2008. These tables show the similar results as those in Tables 1 and 2. Namely, again the variables of BETA and SIZE are statistically significant with the same sign as the mean value of returns of all Japanese electric appliances industry firms on those days in Models 1, 2, and 3 although some exceptions exist. Therefore, our empirical results shown in Tables 1 to 4 indicate that high beta firms and large size stocks move with showing conjunctional behavior when market sentiment is deteriorated. Further, we can also interpret that high beta stocks and large size firms show some different conjunctional behavior because often both variables of BETA and SIZE are simultaneously significant in Model 3 in Tables 1 to 4.

\section{Conclusions}

This paper explored the characteristics of stock return dynamics of the Japanese electric appliances industry when market sentiment is deteriorated. The investigations in this paper derived the following novel contributions.

1. First, this paper newly clarified that high beta stocks presented conjunctional behavior when investor sentiment is deteriorated in stock markets.

2. Second, we clarified that high size stocks also exhibited conjunctional behavior in markets with extremely declined investor sentiment.

3. Furthermore, we also demonstrated that the conjunctional behavior of high beta stocks and high size stocks did not have the same behavioral characteristics in markets with deteriorated investor sentiment.

As above, our novel findings demonstrated in this paper will contribute to the body of academic researches of financial economics. We consider that future related works using our findings and related data may be also valuable, and these works are our future tasks.

\section{Acknowledgements}

The author acknowledges Nick Wade for his kind assistance to this paper. In addition, I also thank anonymous referees for their kind comments to this paper. Furthermore, I greatly appreciate the repeated kind invitation of the Editors to write to this journal.

\section{References}

Alimov, A., \& Mikkelson, W. Does favorable investor sentiment lead to costly decisions to go public? Journal of Corporate Finance, forthcoming. http://dx.doi.org/10.1016/j.jcorpfin.2012.02.004

Baker, M., \& Wurgler, J. A. (2006). Investor Sentiment and the Cross-Section of Stock Returns. Journal of Finance, 61, 1645-1680. http://dx.doi.org/10.1111/j.1540-6261.2006.00885.x

Baker, M., \& Wurgler, J. A. (2007). Investor Sentiment in the Stock Market. Journal of Economic Perspectives, 21, 129-151. http://dx.doi.org/10.1257/jep.21.2.129

Baker, M., Wurgler, J. A., \& Yuan, Y. Global, Local, and Contagious Investor Sentiment. Journal of Financial Economics, forthcoming. http://dx.doi.org/10.1016/j.jfineco.2011.11.002

Barberis, N., Shleifer, A., \& Vishny, R. (1998). A model of investor sentiment. Journal of Financial Economics, 49, 307-343. http://dx.doi.org/10.1016/S0304-405X(98)00027-0

Berger, D., \& Turtle, H. J. (2012). Cross-sectional performance and investor sentiment in a multiple risk factor model. Journal of Banking \& Finance, 36, 1107-1121. http://dx.doi.org/10.1016/j.jbankfin.2011.11.001

Daniel, K., Hirshleifer, D., \& Subrahmanyam, A. (1998). Investor Psychology and Security Market Under- and Overreactions. Journal of Finance, 53, 1839-1885. http://dx.doi.org/10.1111/0022-1082.00077

Kurov, A. (2010). Investor sentiment and the stock market's reaction to monetary policy. Journal of Banking \& 
Finance, 34, 139-149. http://dx.doi.org/10.1016/j.jbankfin.2009.07.010

Lee, C. M. C., Shleifer, A., \& Thaler, R. H. (1991). Investor Sentiment and the Closed-End Fund Puzzle. Journal of Finance, 46, 75-109.

Neal, R., \& Wheatley, S. M. (1998). Do Measures of Investor Sentiment Predict Returns? Journal of Financial and Quantitative Analysis, 33, 523-547. http://dx.doi.org/10.2307/2331130

Stambaugh, R. F., Yu, J., \& Yuan, Y. The short of it: Investor sentiment and anomalies. Journal of Financial Economics, forthcoming. http://dx.doi.org/10.1016/j.jfineco.2011.12.001

Tsuji, C. (2006). Does investors' sentiment predict stock price changes? With analyses of naive extrapolation and the salience hypothesis in Japan. Applied Financial Economics Letters, 2, 353-359. http://dx.doi.org/10.1080/17446540600690136

White, H. (1980). A Heteroskedasticity-Consistent Covariance Matrix Estimator and a Direct Test for Heteroskedasticity. Econometrica, 48, 817-838. 